\title{
INNOVATION AND TRADITION MEET AT TMS2018
}

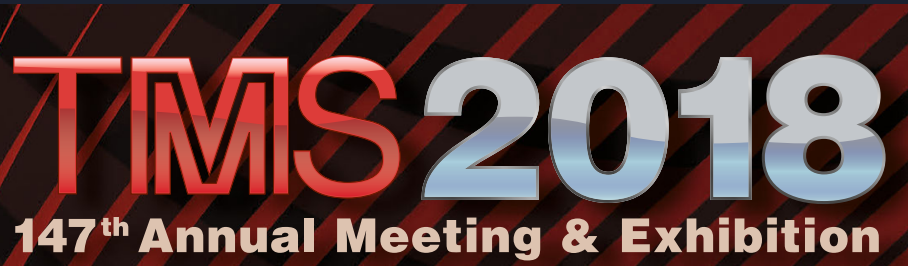

\author{
KELIY ZAPPAS
}

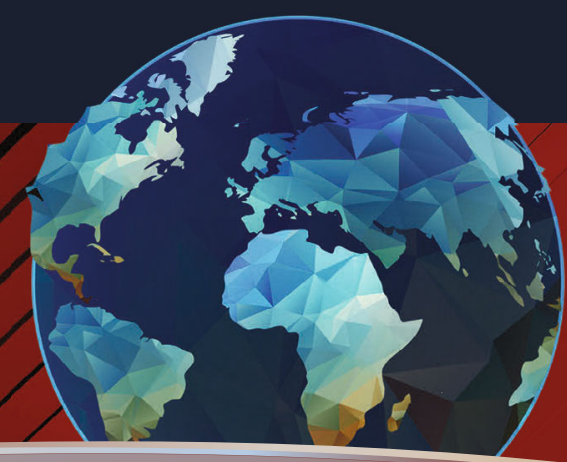

SpaceX and Tesla are two companies with ambitious goals: to enable people to live on other planets and to accelerate the world's transition to sustainable energy, respectively. Innovative use of materials will have a significant role to play in meeting these goals, as Charlie Kuehmann will discuss at the TMS 2018 Annual Meeting \& Exhibition (TMS2018) in Phoenix, Arizona, which will run from March 11 through March 15.

Kuehmann, a TMS member since 1985 who currently leads the materials engineering organizations at both Tesla and SpaceX, will deliver his presentation at a special all-conference plenary session, Defining the Future of Materials and Manufacturing Innovation, planned for Monday, March 12, during TMS2018. His talk will explore potential futures for various industries, within the context of the need for new and innovative materials that can make game-changing advances possible.
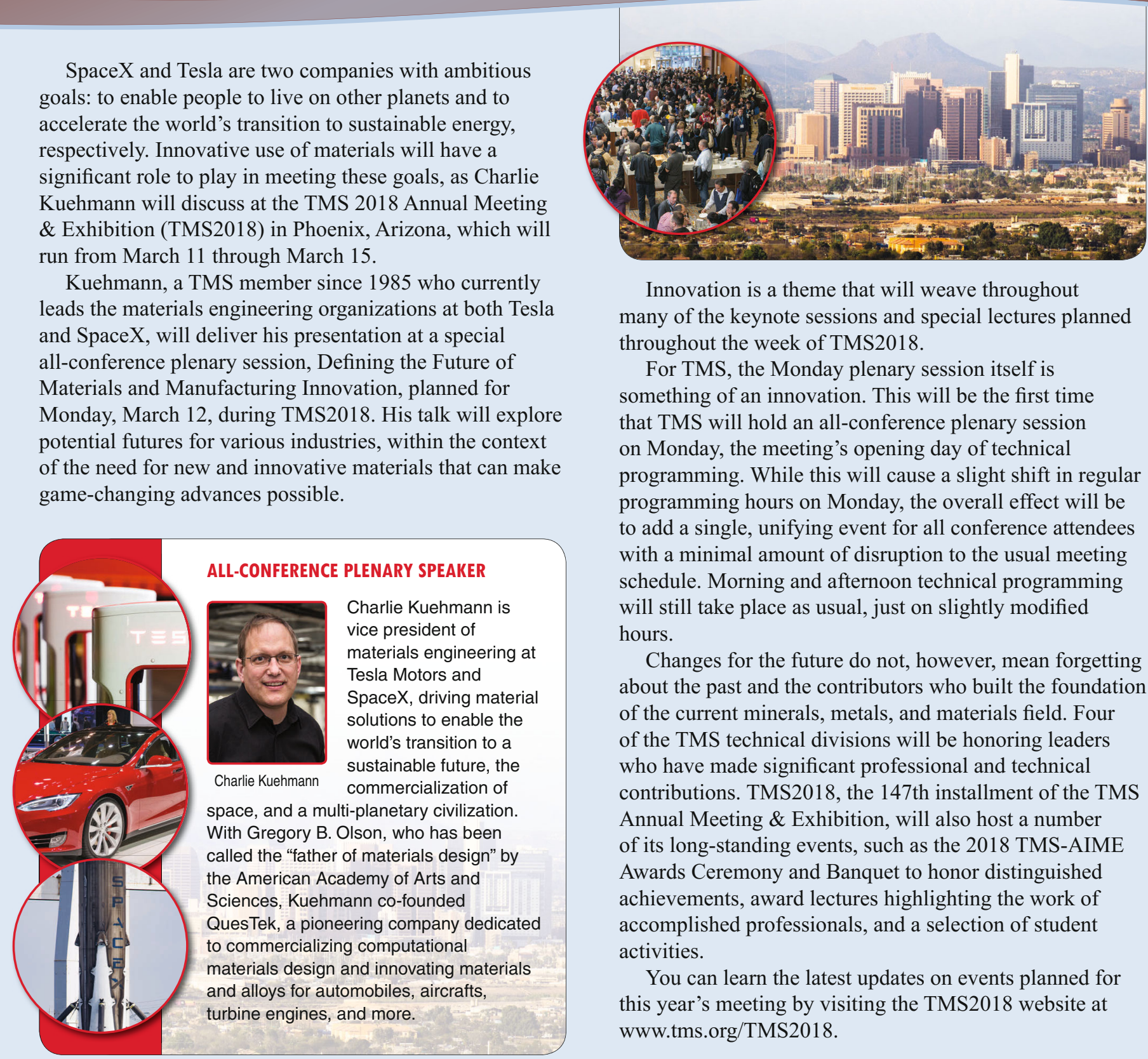

Innovation is a theme that will weave throughout many of the keynote sessions and special lectures planned throughout the week of TMS2018.

For TMS, the Monday plenary session itself is something of an innovation. This will be the first time that TMS will hold an all-conference plenary session on Monday, the meeting's opening day of technical programming. While this will cause a slight shift in regular programming hours on Monday, the overall effect will be to add a single, unifying event for all conference attendees with a minimal amount of disruption to the usual meeting schedule. Morning and afternoon technical programming will still take place as usual, just on slightly modified hours.

Changes for the future do not, however, mean forgetting about the past and the contributors who built the foundation of the current minerals, metals, and materials field. Four of the TMS technical divisions will be honoring leaders who have made significant professional and technical contributions. TMS2018, the 147th installment of the TMS Annual Meeting \& Exhibition, will also host a number of its long-standing events, such as the 2018 TMS-AIME Awards Ceremony and Banquet to honor distinguished achievements, award lectures highlighting the work of accomplished professionals, and a selection of student activities.

You can learn the latest updates on events planned for this year's meeting by visiting the TMS2018 website at www.tms.org/TMS2018. 


\section{The World (Still) Comes Here}

In 2017, when TMS adopted the new tagline "The World Comes Here" for its annual meeting, it was an indication of the organization's strategic focus on international collaboration, as illustrated by its co-locating two international conferences at the TMS2017 meeting site. This year, TMS2018 continues that trend, co-locating with the 2nd International Conference on Computational Design and Simulation of Materials (CDSM 2018), organized by TMS and the Chinese Society for Metals (CSM). Chaired by Zi-Kui Liu of Pennsylvania State University and co-chaired by Alan Luo of the Ohio State University, CDSM will feature symposia on the topics of atomistic simulations, meso/macroscale simulations, and computational design of materials.

TMS is also collaborating with the Federation of European Materials Societies (FEMS) at TMS2018, with plans to hold a keynote symposium on Wednesday of invited talks on the topic of energy and transportation from a European materials perspective. In addition, talks on Nanocellulose Fibrils: A New Constituent in Materials Research will also be presented on Thursday morning.

Visit the TMS2018 website at www.tms.org/TMS2018 for the latest updates on these two programming collaborations.

\section{TMS Honors ...}

Four TMS technical divisions will hold special symposia at TMS2018 in honor of the achievements of distinguished members. This year's honorary symposia will be:

- Coupling Advanced Characterization and Modeling Tools for Understanding Fundamental Phase Transformation Mechanisms: A Materials Processing \& Manufacturing Division Symposium in Honor of Hamish Fraser

- Magnesium Alloy Development: A Light Metals Division Symposium in Honor of Karl Kainer

- Mechanical Characteristics and Application Properties of Metals and Non-metals for Technology: An Extraction \& Processing Division Symposium in Honor of Donato Firrao

- Metal-Matrix Composites Innovations, Advances and Applications: A Structural Materials Division Symposium in Honor of William C. Harrigan, Jr.

\section{Keynotes and More}

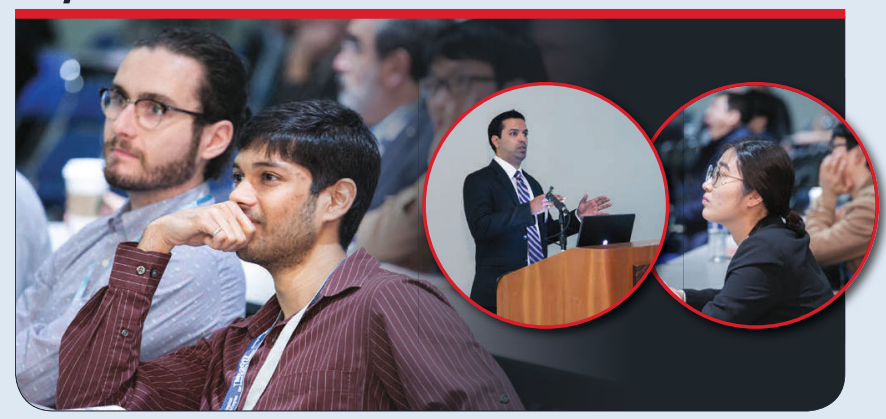

In addition to the all-conference plenary on Monday, TMS2018 will host several special, invited speaker sessions throughout the week, featuring talks by leaders in specialized fields.

Seven symposia are planned on additive manufacturing (AM) topics at TMS2018, and tying them all together will be the Additive Manufacturing Keynote Session, a high-level overview of the state of additive manufacturing throughout the world and in various industries. Ming Leu, Missouri University of Science and Technology, will give an overall introduction to AM technologies, applications, and markets, examining the topics from both a U.S. and a more global perspective. Richard Hague of the University of Nottingham will provide an overview of the AM landscape in the United Kingdom and Europe, while Ma Qian of Royal Melbourne Institute of Technology (RMIT University) will take a closer look at metal additive manufacturing in Australasia and China. For the final three presentations, the discussion shifts from geographical differences to variations in materials. Todd Palmer, Pennsylvania State University, will take a broad look at AM of metals; Dave Rosen, Georgia Institute of Technology/Singapore University of Design, will provide a survey of polymer materials and their AM processes; and Suman Das, Georgia Institute of Technology, will explore ceramics for additive manufacturing.

Three speakers will headline the TMS Materials Innovation Committee's Materials and Manufacturing Innovation Keynote Session at TMS2018, which will look at data and materials: Kristin Persson, University of California, Berkeley; Elizabeth A. Holm, Carnegie Mellon University; and Jed W. Pitera, IBM Research - Almaden. These talks will look at The Materials Project's work, discuss how materials science can capitalize on advances in data science and machine learning, and give a broad overview of big data in the context of materials research \& development. 
The Magnesium Technology symposium, traditionally one of the largest symposia held at the TMS Annual Meeting, opens its programming on Monday, March 12, with a keynote session of invited talks, which this year will include:

- "Magnesium Alloys: Challenges and Achievements in Controlling Performance, and Future Application Perspectives," Karl Ulrich Kainer, MagICMagnesium Innovation Centre, Helmholtz-Zentrum Geesthacht

- "First-principles Evaluation of Solute/Stacking Fault Energies in Magnesium and Implications for Ductility,” Binglun Yin, EPFL

- "Recent Developments in Magnesium Alloy Corrosion Research," Nick Birbilis, Monash University

- "Towards Active Corrosion Protection of Magnesium Alloys Using Corrosion Inhibition Approaches," Mikhail Zheludkevich, MagIC_-Magnesium Innovation Centre, Helmholtz-Zentrum Geesthacht

\section{Luncheon Lectures Bring Divisions Together}

Throughout the week at TMS2018, the society's technical divisions will hold luncheon events that offer division members an opportunity to network, honor outstanding members, and hear from an invited speaker selected by the division leadership. Anyone can view the lecture portion of the event, but tickets are required to attend the luncheon. Tickets can be purchased for $\$ 35$ each during the meeting registration process.

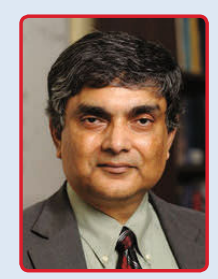

The Structural Materials Division has invited Somnath Ghosh of Johns Hopkins University (JHU) as its luncheon speaker on Monday, March 12. Considered a leader in the field of computational mechanics of materials, Ghosh is the Michael G. Callas Professor in the Department of Civil Somnath Ghosh Engineering and Professor of Mechanical Engineering and Materials Science \& Engineering at JHU. $\mathrm{He}$ is also the founding director of the JHU Center for Integrated Structure-Materials Modeling and Simulation (CISMMS) and the Air Force Center of Excellence in Integrated Materials Modeling (CEIMM). Ghosh leads an internationally recognized research program on multiscale modeling of mechanical behavior and failure response of composite materials, and polycrystalline metals involving structure-material interactions.

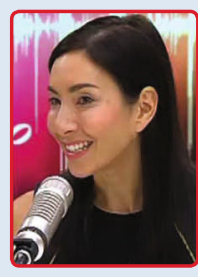

Michelle Dickinson
Michelle Dickinson is the featured speaker at the Extraction \& Processing Division/Materials Processing \& Manufacturing Division Luncheon on Tuesday, March 13. Dickinson is both a senior lecturer in engineering at the University of Auckland, New Zealand, and director of Nanogirl Labs Ltd. Her research group at the University of Auckland specializes in studying the mechanical properties, chemistry and structure of nanomaterials, biological materials, and thin films in addition to standard macro sized materials. Through Nanogirl, she aims to make science and engineering accessible for all and creates new ways for the public to interact with science. She has made television appearances, staged live Theatre Science Shows, produced science communication videos, and records a science comedy podcast called "Stupid Questions for Scientists."

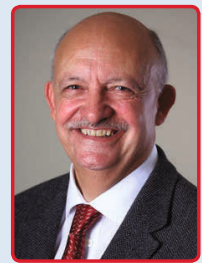

Martin Jarrett
On Wednesday, March 14, Martin Jarrett of Constellium UK Ltd will come to the podium as the Light Metals Division luncheon lecturer. Jarrett, the global technical director of the Automotive Structures \& Industry business unit of Constellium and the technical director of the new Constellium University
Technology Center (UTC) at Brunel University London, will deliver the presentation, "Accelerating the Development of Aluminum Lightweighting Solutions for Crash Management Systems and Structural Automotive Components." His talk will discuss how the importance of being innovative and close to their customers is a driving force within Constellium and their automotive business and how this strategy has broken new ground with the establishment of the UTC. This center aims to bridge the gap between fundamental research and series production, and a key feature of the work of the UTC will be the rapid prototyping of extruded profiles and components to enhance strength and stretch performance limits. His presentation will showcase the equipment and some of the key projects being developed, with a critical focus on the application of high-strength 6xxx alloys for the light weighting of structural automotive parts. 


\section{Professional Development Workshops and Courses Planned}

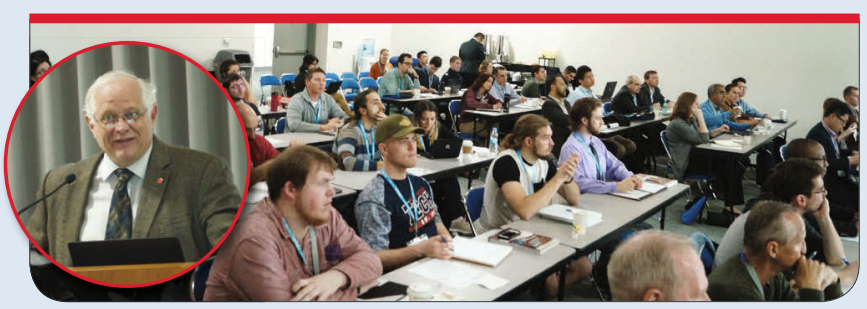

A total of 14 professional development workshops and courses are planned on Sunday, March 11, at the Phoenix Convention Center, prior to the start of technical programming at TMS2018. Course topics include both technical and industrial subjects as well as 'soft' skill topics like career development and leadership. Both full- and halfday courses are planned.

\section{Full-Day Events}

- 14th Annual Advanced Microelectronic Packaging, Emerging Interconnection Technology, and Lead-Free Solder Workshop

- Best Practices in Bauxite and Alumina Processing and Production

- Design of Novel Magnetic Materials by Modelling and Advanced Synthesis and Characterization

- Determination of Sustainability Indicators of Minerals and Metals Using Life Cycle Assessment

- Improving Culture and Business Performance: Going Beyond the Warm and Fuzzy

- Metal Treatment for Aluminum Ingot Casting

- Modeling the Coevolution of Microstructure and Properties using the MOOSE (Multiphysics Object Oriented Simulation Environment) Framework

- Spent Potliner Insights and New Directions

\section{Half-Day Morning Events}

- Hands On: Interactive Materials Data Visualization and Selection Tools for Research and Teaching Workshop (part of the Supplier Technology Education Program)

- Introduction to Alloy Thermodynamics: The CALPHAD Approach and Beyond

- Young Professional Workshop: Preparing a Winning Application Package to Find Your Future Job

\section{Half-Day Afternoon Events}

- Additive Manufacturing Materials and Processes Workshop

- An Introduction to Computational Modeling in Materials Processing

- Avizo 3D Analysis Software for Materials Science (part of the Supplier Technology Education Program)

Learn more about the course topics and meet the expert instructors leading these events in the Professional Development section of the TMS2018 website.

\section{Jump Start Your Career: Young Professional Activities}

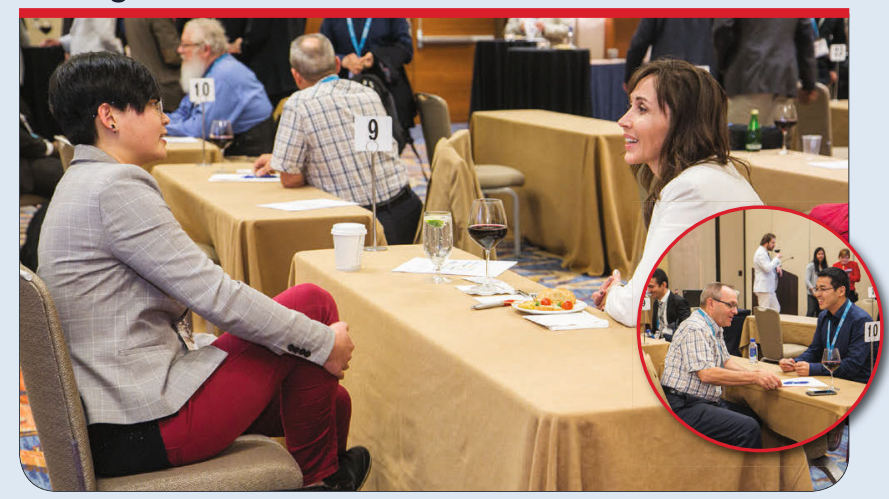

TMS2018 is an ideal place to gather career advice, build professional networks, and establish mentoring relationships. The meeting offers many informal opportunities for these kinds of activities as well as special events specifically designed to facilitate this kind of networking, including:

- TMS101: Held at the beginning of the conference each year, this initiative provides useful information to young professionals and new members about TMS and the TMS Annual Meeting and offers clear instructions on how to make the most of your meeting experience and your TMS membership.

- Meet a Mentor: This popular annual event pairs early career professionals with more senior members of the Society for advice and guidance on professional goals, career paths, and managing work-life balance.

Please check the TMS2018 website for more information on activities geared to the career development of young professionals. 


\section{Programming for TMS2018 and Beyond}

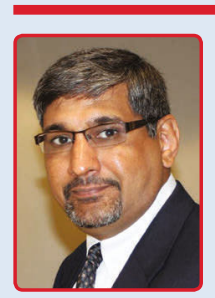

Srinivas Chada, TMS Programming Director

"For the past three years or so, different committees have been working together to create symposia across the division lines. This is a very encouraging trend as these symposia can bridge gaps among committees and reduce redundancy and duplication of topics and papers being presented."

He pointed to the additive manufacturing symposia, which he expects to be a highlight of the annual meeting for 2018 and for the next several years. These symposia are being co-sponsored by all five TMS technical divisions.

Chada's three-year term on the TMS Board of Directors ends at TMS2018, when he will pass his responsibilities on to incoming chair Brad Boyce.

"I foresee no break in the progress we have achieved, as Brad and the volunteers involved in programming were instrumental in the implementation of such initiatives as full rooms until the conference ends, slotted times that allow for prompt start and end of symposia every day, and programming that is not duplicated over several symposia at the same time," said Chada.

For more information, visit the Programming section of the TMS2018 website.

\section{Explore the TMS2018 Exhibition}

The TMS2018 Exhibition will be open Monday, March 12, through Wednesday, March 14, to showcase an international marketplace of products and services. This year, the exhibit hall will host daily lunch breaks for meeting attendees, as well as poster sessions, receptions, and happy hours. Find out which companies will be there and view an interactive floor plan on the TMS2018 website.

Spaces are still available for exhibiting companies. Contact Carly DiVito, TMS2018 Exhibit Manager, Corcoran Expositions, at carly@corcexpo.com. Sponsorship opportunities are also available. Contact Leesa Engelmann, TMS2018 Sponsorship Manager, Corcoran Expositions, at leesa@corcexpo.com.

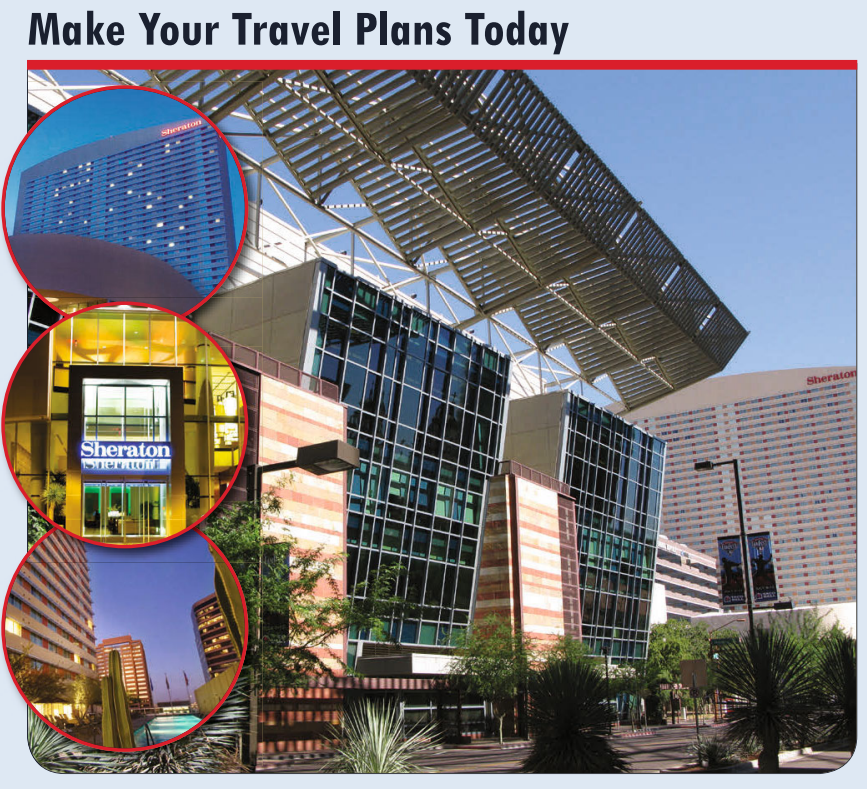

Registration is now open for TMS2018. When you register for the conference, you can also reserve your place at workshops, courses, luncheons, and networking events. (Please note that if you have already registered for the conference, you can log back into the registration website and add an event at any time.) To receive the discounted registration rate on the meeting, you must register by February 1, 2018.

After registering for the meeting, be sure to take the following steps to complete your conference planning. All of these resources can be found under the Registration \& Travel tab of the TMS2018 website.

- Book Housing through TMS: Visit the Housing section of the TMS2018 website to reserve hotel accommodations through onPeak - the official housing provider of the TMS Annual Meeting. The Sheraton Grand Phoenix will serve as the headquarters hotel for this year's conference.

- Apply for a Travel Visa: If you will require a travel visa to enter the United States to attend TMS2018, please apply as soon as possible. You can request a visa invitation letter through the TMS2018 website.

- Apply for Family Care Grants: TMS offers a limited number of grants to help individuals offset family-care expenses associated with the TMS 2018 Annual Meeting \& Exhibition. Grants are available on a first-come, firstserved basis for qualified applicants.

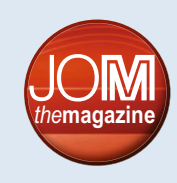

